\title{
PESQUISA EM SEMENTES NO TRÓPICO SEMI-ÁRIDO'
}

\author{
PAULO ANSELMO ANDRADE AGUIAR ${ }^{2}$
}

RESUMO. As pesquisas em sementes na região tropical semi-árida, são desenvolvidas pelo Centro de Pesquisa Agropecuária do Trópico Semi-Ärido da EMBRAPA, pela Empresa de Pesquisa Agropecuária de Pernambuco e pela Universidade Federal do Ceará. Os trabalhos desenvolvidos concentram-se nos problemas relativos a salinidade do solo, tolerância à seca, práticas culturais, sanidade da semente, produção de sementes florestais e ao potencial de uso do vale do Rio São Francisco na produção de sementes.

Termos para indexação: salinidade, tolerância à seca, qualidade de sementes, sanidade da semente, patologia de sementes, produção de sementes.

\section{SEED RESEARCH IN THE SEMI-ARID TROPICAL REGION}

ABSTRACT. Seed research in the semi-arid tropical region are developed by the agricultural Research Center for the Semi-Arid Tropic of EMBRAPA, the Pernambuco State Agricultural Research Enterprise, and the Federal University of Ceará. The seed research projects are concentrated to solve problems related to effects of soil salinity, drought tolerance, forest tree seed production, seed health, cultural practices and to the potential use of the San Francisco river valley to produce seed.

Index terms: salinity, drought tolerance, seed quality, seed health, seed pathology, seed production.

1 Trabalho apresentado no 1 Simpósio Brasileiro de Pesquisa em Sementes, Brasília, DF, 23 a 27.10 .1978 .

2 Engo Agro, Ph.D (Fitotecnia/Sementes), Pesquisador do Centro de Pesquisa do Trópico Semi-Ärido - CPATSA, EM BRAPA. Petrolina, PE. 


\section{INTRODUÇAO}

Com o objetivo de alcançar um melhor desempenho do setor primário da economia do semi-árido, o Centro de Pesquisa Agropecuária do Trópico SemiÄrido (CPATSA) está conduzindo uma programação baseada nas grandes linhas de pesquisa estabelecidas, a nível de Governo Federal, pelo Plano Básico de Desenvolvimento Científico e Tecnológico e a nível regional, pelas políticas estabelecidas pelos órgãos de desenvolvimento do Nordeste. Tal procedimento procura evitar, de um lado, o inoportuno paralelismo de trabalho, e por outro, busca a comunhฐ̃o de esforços para se atingir um objetivo único - diminuir as incertezas com que se opera na agricultura nordestina.

O programa de pesquisa do Centro está constituído por quatro projetos: Projeto de Desenvolvimento de Sistemas de Produção para Áreas de Sequeiro, Projeto Manejo da Caatinga, Projeto de Desenvolvimento de Sistemas de Produção para Áreas Irrigadas e Projeto de Inventários de Recursos Naturais e Ścio-Econômicos.

Os trabalhos de pesquisa em sementes estão enquadrados dentro dos projetos acima referidos, procurando sempre que possível enfocar os problemas caracterizados como limitantes para o desenvolvimento agrícola da região. Assim é que, trabalhos estão sendo conduzidos nas áreas abaixo discriminadas:

Salinidade, Tolerância à seca, Potencial de Produção de Sementes no Vale do São Francisco, Efeito de Práticas Culturais na Produção e Qualidade da Semente, Patologia de Sementes, Produção de Sementes Florestais.

$O$ presente documento é uma tentativa de reunir algumas informações de pesquisa em sementes no Trópico Semi-Árido incluindo as realizadas no CPATSA, IPA e UFC. Deve-se salientar que os trabalhos citados não englobam todas as pesquisas em realização, mas, apenas constituem exemplos do que vem sendo feito em sementes no Nordeste.

\section{ÁREAS de PESQUISA}

\section{Salinidade}

Nas regiōes áridas e semi-áridas do mundo, o excesso de sais em áreas agricolas tem limitado a produção das culturas, principalmente nos perímetros irrigados. Estima-se que no Nordeste, cerca de $25 \%$ dos perímetros irrigados em operaçăo àpresentam problemas de sais (SUDENE, 1977). 
O CPATSA, através de sua equipe multidisciplinar vem encarando esta situação com grande seriedade, e tem procurado atacar o problema considerando o complexo solo-água e planta como um todo.

No que diz respeito a parte da planta, sabe-se que a resistência ou tolerância à salinidade varia nos diversos estágios de desenvolvimento da cultura, sendo que, na germinaçáo e primeiros estágios de desenvolvimento, o efeito nocivo dos sais é bem mais severo do que nas etapas posteriores. Este efeito é de natureza osmótica (limitada absorçáo d'água pela semente ou pela planta) e de natureza tóxica (penetração excessiva de íons dos sais nos tecidos celulares).

O excesso de sais no solo proporciona uma diminuição na percentagem e velocidade de germinação das culturas. $O$ fato de que as sementes viáveis, germinam lentamente ou não germinam quando plantadas, resulta em stands desuniformes, com reflexos negativos na produção.

No tocante a parte de Tecnologia de Sementes, foram executados ou estão programados os trabalhos: Efeito da salinidade na germinação e vigor das sementes, Pré-tratamento de sementes como meio de minorar os efeitos da salinidade na germinação e vigor e, Pré-tratamento de sementes como meio de aumentar a produção das plantas cultivadas em solos salinos.

Efeito da salinidade na germinação e no vigor das sementes: este trabalho consta de duas partes:

a. Screening de cultivares: partindo-se das coleçб̋es de cultivares de arroz, sorgo, milho, existentes na região, serão selecionadas as que apresentem maior resistência ou tolerância à sais durante a germinação e primeiros estágios de desenvolvimento; serão feitas observações de percentagem de germinação e vigor nas diferentes cultivares que serão semeadas em substrato salino e não salino (controle).

b. Efeito da salinidade na germinação e no vigor de hortaliças: visa identificar cultivares de cebola, melão, tomate e melancia atualmente plantadas no Vale do São Francisco, tolerantes às condições salinas, bem como identificar os niveis de salinidade que possam acarretar perdas na germinação e desenvolvimento inicial da planta.

Este trabalho está sendo realizado com um número limitado de cultivares e com um número mais elevado de soluções salinas de modo a permitir a identificação do nível salino responsável por perdas substanciais na germinação e vigor das plantas.

Trabalhos iniciais foram conduzidos por Aguiar (1977a) e Aguiar e Pereira (1978) com as culturas de cebola (Tabela 1) e melão (Tabela 2). Os resultados de germinação de cebola revelam existir diferença significativa entre as cultivares estudadas e que a germinação decresce progressivamente com o aumento da 
Tabela 1 - Efeito da salinidade na germinação de 3 cultivares de cebola ${ }^{1}$.

\begin{tabular}{cccccc}
\hline $\begin{array}{c}\text { Niveis de } \\
\text { Salinidade } \\
(\%)\end{array}$ & $\mathrm{CE}_{25}{ }^{\circ} \mathrm{C}$ & \multicolumn{3}{c}{ Germinação (\%) } & Média \\
\cline { 3 - 5 } & & $\begin{array}{c}\text { Red } \\
\text { Creoule }\end{array}$ & $\begin{array}{c}\text { Texas } \\
\text { Grano }\end{array}$ & $\begin{array}{c}\text { Hybrid } \\
\text { Granex }\end{array}$ & (\%) \\
\hline 0,00 & 0,09 & 96 & 96 & 82 & $91 \mathrm{a}$ \\
0,05 & 1,06 & 96 & 94 & 80 & $90 \mathrm{ab}$ \\
0,10 & 1,92 & 97 & 94 & 79 & $90 \mathrm{ab}$ \\
0,20 & 3,33 & 97 & 92 & 78 & $89 \mathrm{~b}$ \\
0,30 & 4,55 & 89 & 85 & 78 & $84 \mathrm{~b}$ \\
0,50 & 7,14 & 88 & 74 & 69 & $77 \mathrm{c}$ \\
\hline Média (\%) & & $84 \mathrm{~A}$ & $89 \mathrm{~B}$ & $87 \mathrm{C}$ & \\
\hline
\end{tabular}

1 Médias seguidas da mesma letra não diferem significativamente ao nível de $5 \%$, segundo o teste de Duncan.

Tabela 2 - Efeito da salinidade na \% de germinação, peso seco e peso verde das plântulas de melão, cultivar Amarelo CAC ${ }^{1}$.

\begin{tabular}{ccccc}
\hline $\begin{array}{c}\mathrm{CE}_{\mathbf{2 5}}{ }^{\circ} \mathrm{C} \\
(\mathrm{mmho} / \mathrm{cm})\end{array}$ & $\begin{array}{c}\text { Pressão } \\
\text { Osmótica } \\
\text { da Solução } \\
(\mathrm{atm})\end{array}$ & $\begin{array}{c}\text { Germinação } \\
\%\end{array}$ & $\begin{array}{c}\text { Peso Seco } \\
(\mathrm{g})\end{array}$ & $\begin{array}{c}\text { Peso Verde } \\
(\mathrm{g})\end{array}$ \\
\hline 1,03 & 0,37 & $91,0 \mathrm{a}^{*}$ & $5,44 \mathrm{a}$ & $66,82 \mathrm{ab}$ \\
2,13 & 0,77 & $93,0 \mathrm{a}$ & $5,68 \mathrm{a}$ & $69,83 \mathrm{a}$ \\
2,86 & 1,03 & $94,5 \mathrm{a}$ & $5,54 \mathrm{a}$ & $68,47 \mathrm{ab}$ \\
4,71 & 1,70 & $92,5 \mathrm{a}$ & $4,48 \mathrm{a}$ & $55,13 \mathrm{~b}$ \\
6,27 & 2,26 & $69,5 \mathrm{~b}$ & $1,83 \mathrm{bc}$ & $27,13 \mathrm{c}$ \\
7,34 & 2,64 & $50,5 \mathrm{c}$ & $1,94 \mathrm{~b}$ & $21,17 \mathrm{c}$ \\
9,46 & 3,40 & $15,0 \mathrm{~d}$ & $0,53 \mathrm{c}$ & $5,37 \mathrm{~d}$ \\
\hline Tukey (5\%) & & 12,3 & 1,36 & 13,87 \\
$\mathrm{CV}(\%)$ & & 8,7 & 16,1 & 13,25 \\
\hline
\end{tabular}

i Médias em uma mesma coluna seguidas da mesma letra nâo diferem significativamente ao nível de $5 \%$ pelo teste de Tukey. 
concentração salina do substrato. O nivel mais alto de concentração do substrato (C.E. $25^{\circ} \mathrm{C}=7,14 \mathrm{mmho} / \mathrm{cm}$ ) é considerado apenas moderadamente salino (Handbook n? 60 USDA).

$\mathrm{Na}$ Tabela 2, constata-se o efeito da salinidade na germinação e vigor de sementes de melão, cultivar Amarelo CAC, atualmente o único cultivado na região. Observa-se, também, uma queda na germinação e vigor com o aumento da salinidade, sendo bem acentuada ao nivel de $\mathrm{CE}_{25} \circ \mathrm{OC}=6,27 \mathrm{mmho} / \mathrm{cm}$. Estes resultados parciais demonstram que o cultivo da cebola e melão podem ser seriamente prejudicados tanto em germinação como no desenvolvimento inicial das plântulas quando plantadas em solos salinos, ou seja, solos com condutividade elétrica superior a $4\left(\mathrm{CE}_{25}{ }^{\circ} \mathrm{C}>4 \mathrm{mmho} / \mathrm{cm}\right)$.

Pre-tratamento de sementes como meio de minorar os efeitos da salinidade na germinação e no vigor: $O$ pré-tratamento de embebição e secagem das sementes antes do plantio, tem sido usado como meio para aumentar a resistência das plantas à seca (Genckel, 1964). Este processo tem sido aplicado também em sementes (Prisco, 1977) e em plantas (Strogonov, 1959), visando aumentar à resistência às condições salinas do meio.

Sementes pré-tratadas (embebição e secagem) e sementes sem receber tratamento (controle), serão semeadas em substratos com diferentes concentrações salinas e serão observados a germinação e o vigor das sementes.

Pré-tratamento de sementes como meio de aumentar a produção das plantas cultivadas em solos salinos: um estudo paralelo ao efeito da pré-embebição e secagem na germinação e vigor, será conduzido sob condiçóes de campo para testar a eficácia do método em sobrepujar os efeitos inibitórios da salinidade no crescimento e desenvolvimento da planta.

\section{Toleråncia à seca}

A irregular distribuição e a insuficiência de chuvas no período de crescimento das culturas tem causado sérios transtornos à economia nordestina. 0 desenvolvimento de tecnologia que propicie uma maior estabilidade agrícola necessita ser estudada sob todos os aspectos. Trabalhos estão sendo desenvolvidos utilizando-se métodos e técnicas empregados em sementes, visando propiciar às culturas do trópico semi-árido um maior índice de tolerância à seca.

Pré-tratamento de hidratação-desidratação das sementes como método de resistência à seca: foi sugerido por Genckel, (1964), um método para aumentar a resistência das plantas às condiçōes de seca. Trata-se do "hardening", ou seja, a hidratação e desidratação das sementes antes do plantio. Este método propicia 
mudanças de natureza físico-química do citoplasma, havendo uma maior hidratação dos colóides; uma maior viscosidade e elasticidade do protoplasma; uma maior quantidade de água de composição e um metabolismo mais intenso. Os resultados destas mudanças determinam uma série de outras peculiaridades, tais como: estrutura mais xeromórfica das plantas; menor déficit d'água; maior capacidade de retenção de umidade e um sistema radicular mais eficiente.

Por outro lado, o método sugerido aumenta o número de colóides hidrofilicos com um decréscimo dos lipofílicos; há uma diminuição do ponto isolétrico das proteínas, com um aumento da temperatura necessária para coagulação das mesmas.

Os resultados práticos obtidos por vários autores revelam um substancial aumento na produção de plantas oriundas de sementes tratadas. Todavia, o sucesso do método depende da técnica de hidratação-desidratação utilizada, do periodo e época de estiagem no desenvolvimento da cultura, bem como da própria cultura.

Trabalhos preliminares estão sendo conduzidos no CPATSA com a cultura do milho, na tentativa de identificar a técnica de hidratação e desidratação das sementes, bem como trabalhos iniciais estão sendo conduzidos sob condições de campo, para testar a viabilidade do método.

Pré-tratamento de hidratação-desidratação das sementes como meio de minorar os efeitos do stress hídrico na germinação e vigor: o plantio e estabelecimento da cultura dependem do nível de umidade no solo para propiciar uma germinação uniforme. Todavia, sob as condições do trópico semi-árido, onde normalmente as chuvas são incertas, o nivel de umidade exigido para a germinação quase sempre não é atingido. Isto, proporciona uma baixa e desuniforme germinação. $O$ prétratamento de hidratação-desidratação das sementes está sendo testado sob condiçōes de laboratório, como meio de minorar os efeitos do stress hídrico na germinação e vigor das sementes.

Screening de cultivares através de simulação: investigações recentes tem tentado avaliar a eficácia da germinação e vigor das sementes, sob diferentes concentraçōes osmóticas como uma técnica de avaliar material genético para condições limitadas de água. Esta técnica além de rápida, permite a avaliação de um grande número de cultivares. A germinação e vigor das diversas cultivares sob diferentes concentrações osmóticas do substrato será correlacionado com a performance das cultivares sob condições de stress hídrico em campo.

\section{Potencial de produção de sementes no Vale do São Francisco}

Como se sabe, grande parte das sementes de hortaliças comercializadas no 